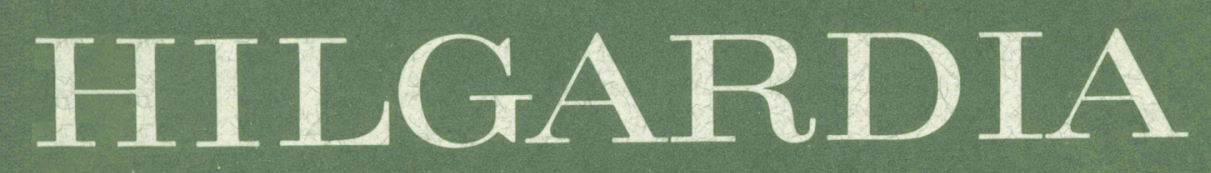

AJOURNAL OF AGRICULTURAL SCIENCE PUBLISHED BY THE CALIFORNIA AGRICULTURALEXPERIMENT STATION

Volume 47, Number $5 \cdot$ November, 1979

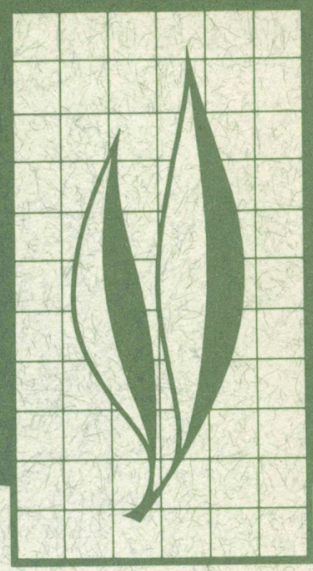

\title{
Some Interactions of the
} Pink Bollworm

and Cotton Fruiting Structures

D. F. Westphal, A. P. Gutierrez, and G. D. Butler, Jr. 


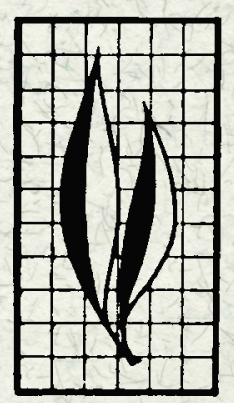

A study was initiated in Phoenix, Arizona, to discern and quantify the interactions between the pink bollworm and cotton plants. Fruit abundance and the pink bollworm larval population contained within fruits were monitored through time. The following interactions and phenomena were considered: specific ages of fruit preferred by the pink bollworm, characteristics of surviving fruit, pink bollworm-induced fruit abscission, survival of first instar pink bollworms in relation to fruit age attacked, and the effects of pink bollworm feeding on cotton squares. Results of this study indicated that 1) pink bollworms do not significantly affect shed rates of cotton fruits; 2) pink bollworm survival is greatest in older bolls; and 3) older bolls are preferred for pink bollworm attack.

\section{THE AUTHORS:}

D. F. Westphal was Post-Graduate Research Entomologist, Division of Biological Control, Department of Entomological Sciences, Berkeley. A.P. Gutierrez is Entomologist, Division of Biological Control, Department of Entomological Sciences, Berkeley.

G. D. Butler, Jr., is Entomologist, Agricultural Research Service, USDA, Phoenix, Arizona. 


\section{Some Interactions of the Pink Bollworm and Cotton Fruiting Structures ${ }^{1,2}$}

\section{INTRODUCTION}

THE PINK BOLLWORM, Pectinophora gossypiella (Saunders), was originally described in 1843 from specimens collected in India where it is thought to be indigenous (Noble, 1969). Brazzel and Gaines (1956) estimated that this pest reduced the value of the cotton crop in the southwestern United States by 30 percent.

Most of the loss caused by the pink bollworm (PBW) is due to quality reduction of the seed and lint, while actual yield reductions occur only when infestations become abnormally high, i.e., 100 percent bolls infested with over 10 larvae per boll (Brazzel and Gaines, 1956). Adkisson (1960) reported a reduction in quality when 60 percent of the bolls were damaged. Lukefahr and Martin (1963) concluded it was necessary to have a 50 percent boll infestation and two larvae per boll before value of the cotton crop was decreased. In fact, yields and quality are also mitigated by boll rot, aflotoxins in the seed, and other such factors.

Pink bollworm damage directly and indirectly causes all of this loss. For these reasons, the growth habits and behavior of the pests and plants, both separately and as they interact, must be discerned and quantified if damage is to be accurately assessed and effective control programs designed. This study was undertaken to examine and express mathematically such plant-pest interactions as fruit age preferred by adult pink bollworm, characteristics of "survivor" fruit, and the like, in order to refine the population model (Gutierrez et al., 1977).

\section{MATERIALS AND METHODS}

\section{Field observations}

Field observations were conducted on Deltapine 16 cotton variety at the Arizona State University Farm in Tempe, Arizona, during the summer of 1975 . The experimental area consisted of 20 rows of cotton plants, each row 100 meters in length. Rows were oriented in an east to west direction; the field sloped to the west.

Five plants were collected three times a week with collections alternating between the east and the west ends of the field. Maps by node of each of the five plants were drawn which showed the presence and size of fruit and shed scars as they occurred (Gutierrez et al., 1975). All fruits collected from the five sample plants were dissected and carefully examined for pink bollworm larvae. Bolls were sectioned with a scalpel along natural sutures. Pink bollworms recovered from dissections were placed on an artificial

${ }^{1}$ Accepted for publication October 11, 1978.

2This publication was supported in whole or in part by the National Science Foundation and the Environmental Protection Agency, through grants (NSF DEB-75-04223 and NSF DEB-77-25260) to the University of California. The findings, opinions, and recommendations expressed herein are those of the author(s) and not necessarily those of the University of California, the National Science Foundation or the Environmental Protection Agency. 
diet using a moist camel hair brush and kept in an incubator at a constant temperature $\left(30.3^{\circ} \mathrm{C}\right)$ until pupation was complete.

\section{PBW oviposition site preference}

The commonly accepted terms for fruit developmental stages are square (bud), flower, and boll (seed and lint maturation stage). When contemplating insect control methods, it is important to know the stage and age of fruit that is most susceptible to pink bollworm attack. The selection of oviposition sites is made by the adult females. The eggs are normally laid on or near specific fruiting structures (Noble, 1969) but some ages (stages) of fruit are more preferred than others, and the proportion of the eggs deposited on each stage changes with their availability. Hence, it is important to ascertain this preference as a function of fruit age and availability. Direct observation of insect oviposition is the best way to determine preference, but the nocturnal habits of the insect make this difficult, if not impossible. Fortunately, direct observation is not the sole method available for obtaining such data. If one knows the time of pupation of the insect (in media), and the age of the fruit at collection, one can calculate the age of fruit when it was chosen for oviposition. In addition, the date of egg laying also can be calculated using these same age values in conjunction with daily records of degree day accumulations $\left(\mathrm{D}^{\circ}\right)$. These calculations are presented in the Appendix. The calculations and assumptions used for estimating $D^{\circ}$ are reviewed by Campbell et al. (1974). The estimated threshold for cotton growth and development is $12^{\circ} \mathrm{C}$ (Gutierrez et al. 1975), while that for the pink bollworm is $10^{\circ} \mathrm{C}$ (Butler and Hamilton, 1976).

The developmental time $\left(\mathrm{D}^{\circ}\right)$ of individual fruit was divided into ten categories. The square stage consists of four nearly equivalent (approximately $130 \mathrm{D}^{\circ}$ ) age categories labeled, from smallest to largest, $\mathrm{Sa}, \mathrm{Sb}, \mathrm{Sc}$, and $\mathrm{Sd}$. There was a single category of flower age,

TABLE 1.

DEVELOPMENTAL TIMES FOR COTTON AND PINK BOLLWORM (PBW) IN DEGREE-

DAYS $\left(\mathrm{D}^{\circ}\right)$ ABOVE THE THRESHOLDS OF $12^{\circ} \mathrm{C}$ AND $10^{\circ} \mathrm{C}$, RESPECTIVELY, AND APPROPRIATE SCALARS ( $\delta$ ) FOR THE DEVELOPMENTAL TIME OF THE LARVAL STAGE AS INFLUENCED BY THE AGE OF FRUIT*

\begin{tabular}{|c|c|c|c|c|}
\hline \multirow{2}{*}{$\begin{array}{l}\text { Stage of fruit } \\
\text { and size }\end{array}$} & \multirow{2}{*}{$\begin{array}{c}\text { Age range } \\
\left(D^{\circ}\right)\end{array}$} & \multicolumn{3}{|c|}{ PBW } \\
\hline & & $\begin{array}{c}\text { Scalors }(\delta) \text { for } \\
\text { development rate }\end{array}$ & Stage & $\mathbf{D}^{\circ}$ \\
\hline $\mathrm{Sa}$ & $0-152$ & 1.00 & & \\
\hline $\mathrm{Sb}$ & $152-279$ & 0.94 & & \\
\hline Sc & $279-402$ & 0.72 & Egg & $0-83$ \\
\hline$S d$ & $402-527$ & 0.58 & Larval & $84-322$ \\
\hline $\mathrm{Fl}$ & $527-544$ & 1.60 & Pupal & $323-450$ \\
\hline $\mathrm{Ba}$ & $544-694$ & 1.60 & & \\
\hline $\mathrm{Bb}$ & $694-861$ & 1.00 & \{ Pre-reproductive & $451-478$ \\
\hline $\mathrm{Bc}$ & $861-1027$ & 0.96 & Reproductive & $479-794$ \\
\hline $\mathrm{Bd}$ & $1027-1166$ & 0.88 & & \\
\hline $\mathrm{Bm}$ & $1166-1277$ & 0. & & \\
\hline
\end{tabular}

" $\mathrm{S}=$ square stage (a, smallest, through d, largest); $\mathrm{Fl}=$ flower;

$B=$ boll (a, smallest, through d, largest).

SOURCE: Developmental times from Lukefahr (1962) and development scalars from Gutierrez et al. (1977). 
$\mathrm{Fl}$, and four nearly equivalent age categories of bolls, from smallest to largest, $\mathrm{Ba}, \mathrm{Bb}, \mathrm{Bc}, \mathrm{Bd}$. The last category is an open mature boll, Bm (see Table 1).

Twenty bolls were collected in each of the four age categories on four different occasions. Bolls were measured with a clear millimeter ruler at the greatest transverse diameter and weighed after they had been dried thoroughly in an oven.

\section{Cage studies}

Premature abscission reduces the number of fruits reaching maturity and hence may affect yield. For this reason a study was initiated to determine the effect of pink-bollworm feeding on the probability of abscission of fruits in the different age classes, i.e., age-dependent fruit survivorship.

In these tests, small nylon bags were constructed to enclose individual fruiting structures. A drawstring was used to close each bag at the stem end of the fruit, and a small piece of foam rubber was used to make an insect-proof seal around the stem and to prevent damage to the stem when the drawstring was tightened. A wire placed in a seam within the cage kept the bag from collapsing on the fruit.

Five newly hatched first instar pink bollworm larvae were placed on some fruiting structures using a moistened camel hair brush; controls were left uninfested. A colored, dated, identifying tag was attached to each fruit. Experimental plants were stripped of all fruit except for those contained in the cages, so that plant-induced shedding due to carbohydrate stress was minimized (Gutierrez et al., 1975). The rate of the pink bollworm-induced shed was determined by comparing the rate of shed between infested and uninfested fruit. In addition, data were obtained on the effects of fruit age on the rate of successful pink bollworm infestation. The relationships between the percent successful infestation rate and survivorship of the fruits on fruit age class are described by regression equations.

\section{RESULTS}

\section{The plant}

The persistence of fruit on the plant (fruit survivorship) and the age structures (number per age class) of fruit population influence the dynamics of cotton growth and development (see Wang et al., 1977; Gutierrez et al., 1975) and directly influence the population dynamics of the pink bollworm (Gutierrez et al. 1977).

\section{Fruit population age structure}

More bolls were produced in the west end of the field than in the east end, probably because the plants received more of the westward-draining irrigation water. Plants in the east end of the field were smaller, showed water stress and often wilted between irrigations. The abundance of small squares, approximately 0 to 279
$\mathrm{D}^{\circ}$; large squares, approximately 279 to $527 \mathrm{D}^{\circ}$; and small bolls, approximately 544 to $861 \mathrm{D}^{\circ}$; large bolls, approximately 861 to $1166 \mathrm{D}^{\circ}$ are plotted as a function of day degrees (Figs. 1, 2, 3, and 4, respectively). Two linear regressions estimate fruit abundance for each category of fruit. The first regression line estimates increase in fruit abundance, while the second regression line estimated the decrease.

\section{Intrinsic fruit survivorship}

Cotton plants commonly shed fruit when they suffer carbohydrate stress (Gutierrez et al. 1975). Age-specific fruit survivorship (percentage of nonshed fruit) was regressed on fruit age and gave a significant relationship $\left(R^{2}=0.38\right.$, see Fig. 5). A test of regression $(t=$ 


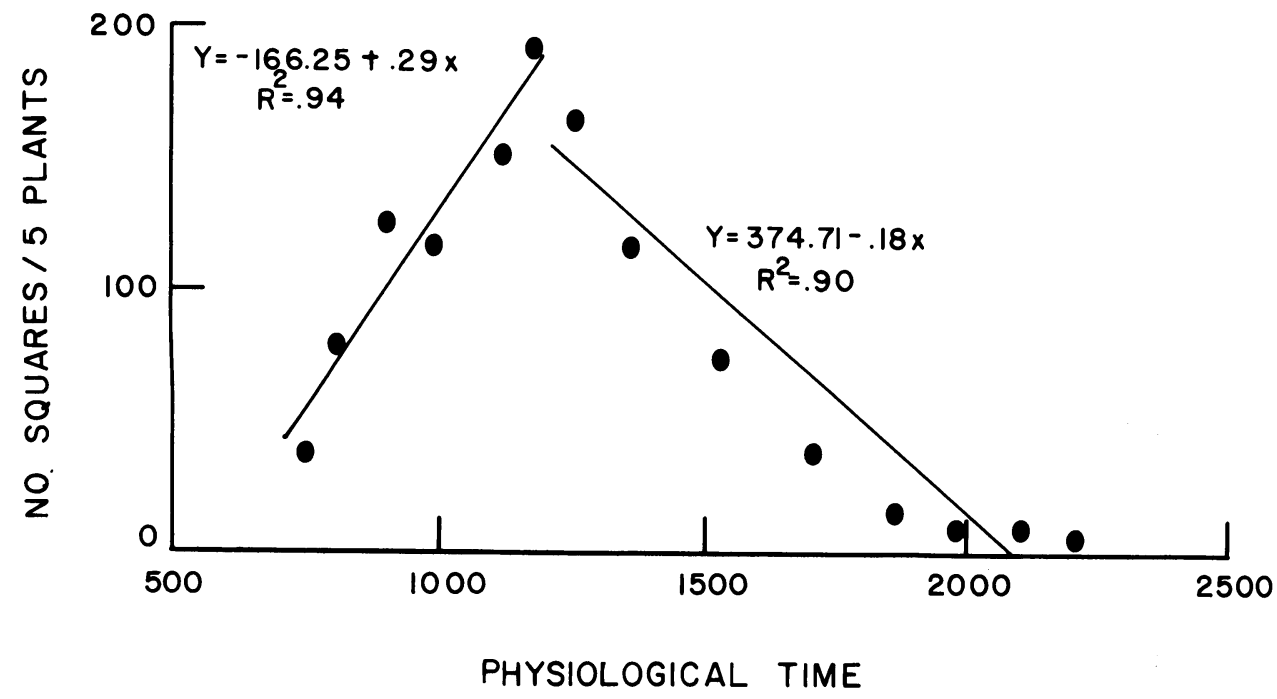

Fig. 1. Regression equations showing the increase and decrease of small square abundance (per 5 plants) as a function of degree-days.

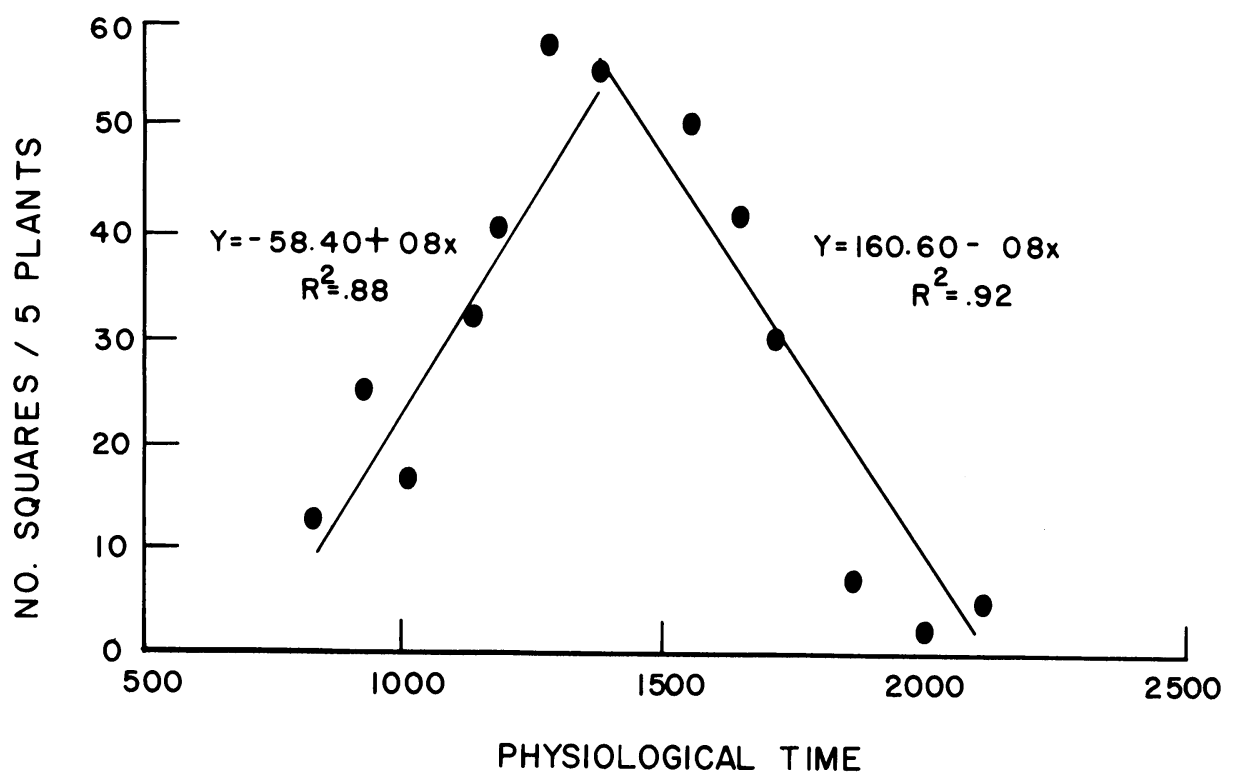

Fig. 2. Regression equations showing the increase and decrease of large square abundance (per 5 plants) as a function of degree-days.

9.494, $\mathrm{df}=7$, two-tailed test, $\alpha=.05$ ) showed that the slope of the line was not equal to zero, while a test of linearity $(\mathrm{F}=1.25, \mathrm{~F}(.05, \mathrm{df} 7,90)=2.11)$ further supports the validity of the model which states that survivorship increases as fruits mature. Very small squares have the lowest survival rate, while larger bolls approach a survival rate of 1 (i.e., they are rarely shed under any circumstances).

\section{Relationship of insect-abundance to plant stage}

Pink bollworm abundance is greatly affected by the age structure of the fruit populations, because the fecundity of 


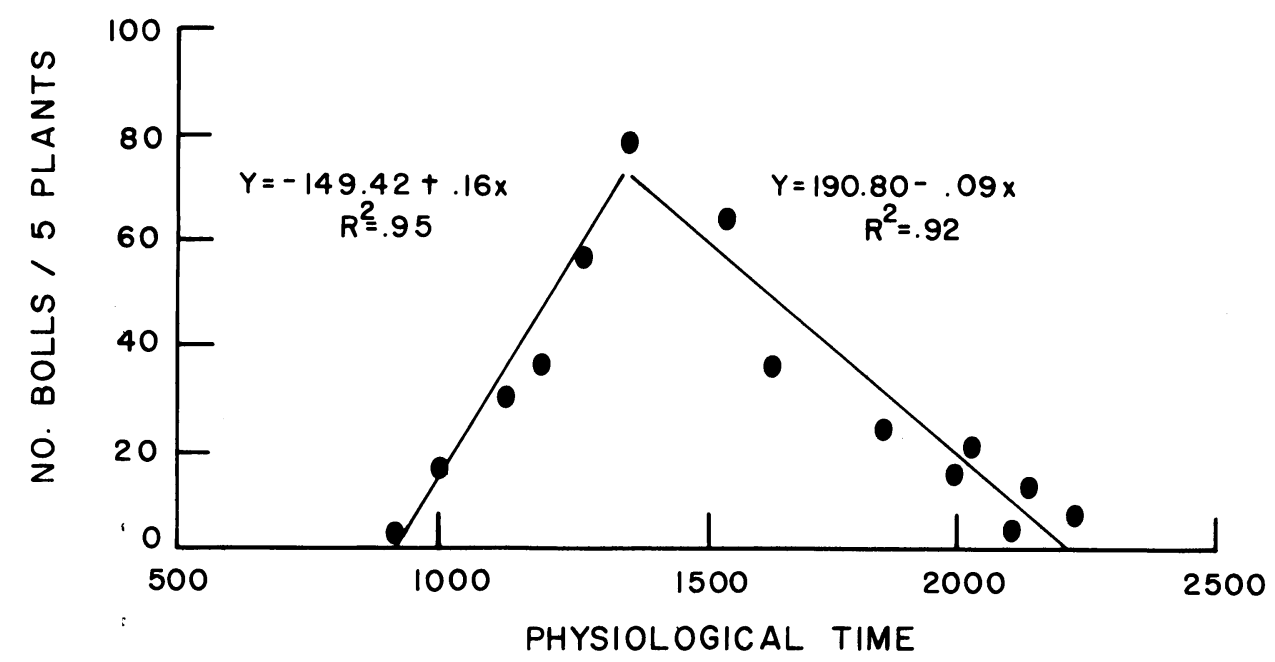

Fig. 3. Regression equations showing the increase and decrease of small boll abundance (per $S$ plants) as a function of degree-days.

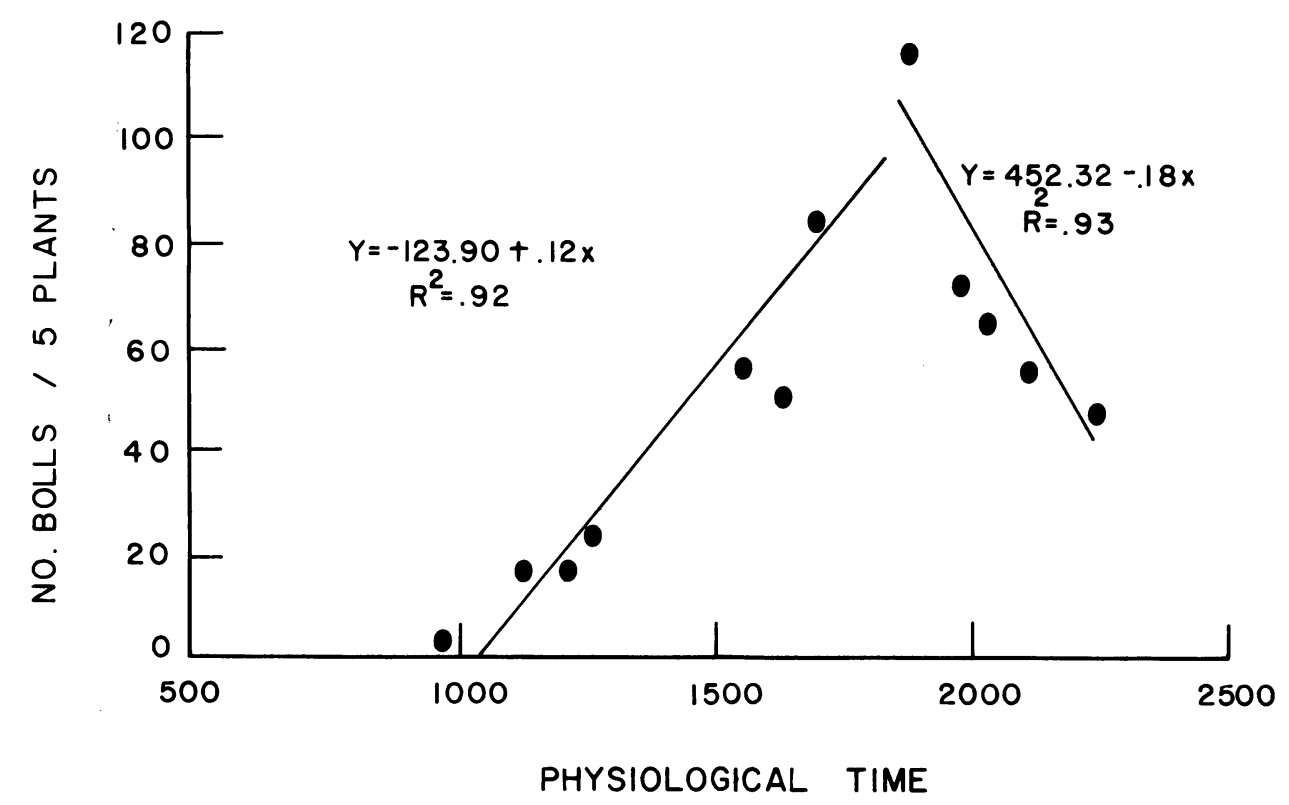

Fig. 4. Regression equations showing the increase and decrease of large boll abundance (per 5 plants) as a function of degree-days.

pink bollworm females is greatly influenced by the age of the fruit they were reared on. For example, females reared on bolls produce $160 \pm 14$ eggs, while those reared on squares produce $125+10$ eggs (McLaughlin, 1972). Also, many pink bollworms can develop in a single boll, while typically only one larva develops per square (Brazzel and Martin,
1955). Adkisson (1961) reported that boll-reared females produced approximately twice as many eggs as females reared on squares. The preoviposition period of the square-reared females was significantly longer than that of bollreared females (Adkisson, 1961). Dependence of this insect on bolls for rapid population development makes the pink 


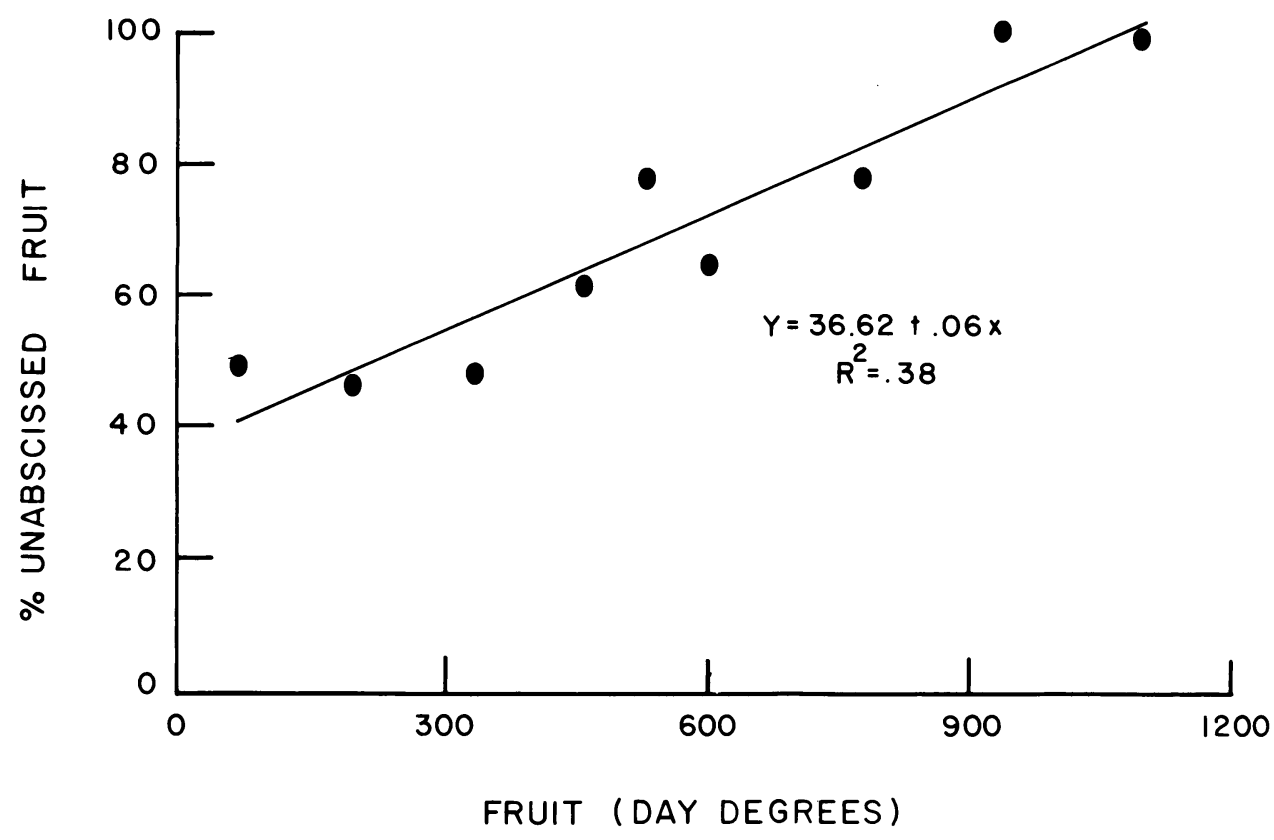

Fig. 5. Regression equation showing the percent of unabscissed fruit (mean values) and fruit age in degree-days.

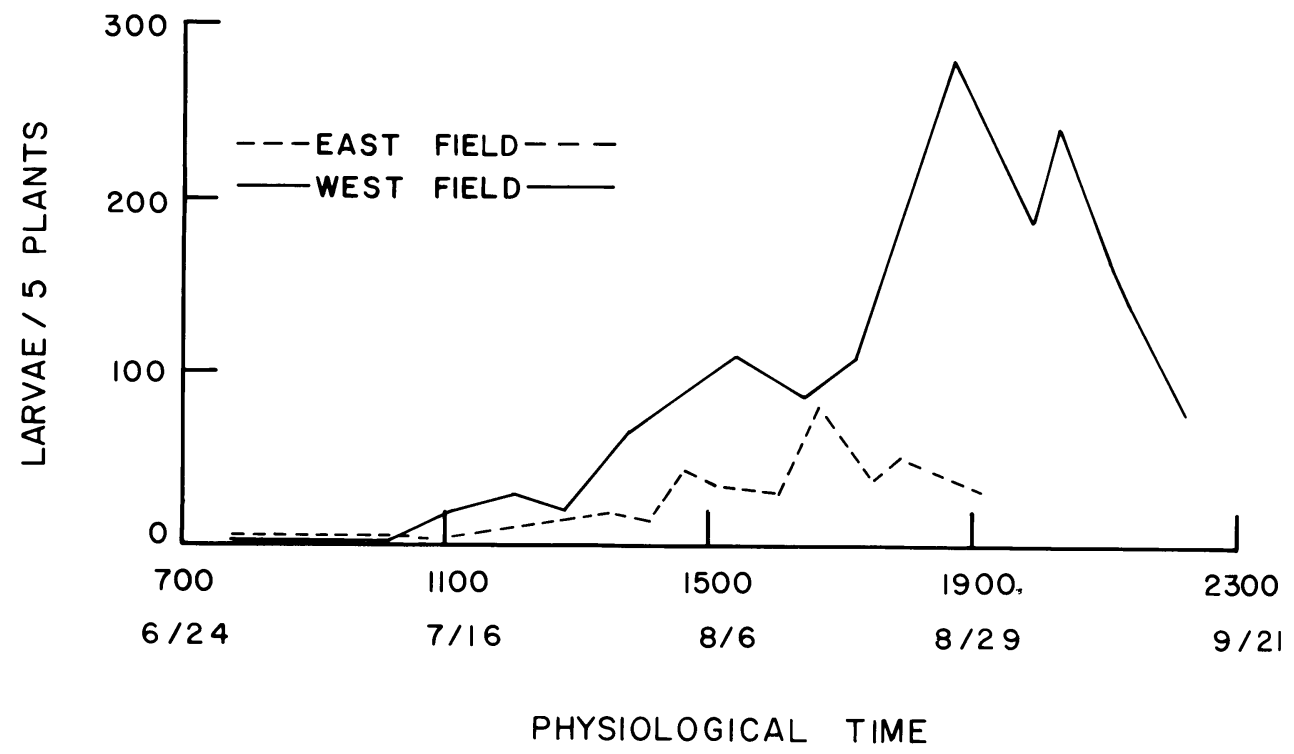

Fig. 6. Abundance of pink bollworm larvae dissected from cotton fruits (per 5 plants) is plotted on cummulative degree-days for both the east and west ends of the field.

bollworm a mid- to late-season cotton pest (Slosser and Watson, 1971).

A larger population of pink bollworms developed in the west end of the field than in the east end (Fig. 6) probably because of its greater number of avail- able fruiting structures. There were four distinct generations, the timing of which was dependent upon the appearance of fruiting structures, and infestation levels remained at low levels until the appearance of bolls. Most infested squares de- 


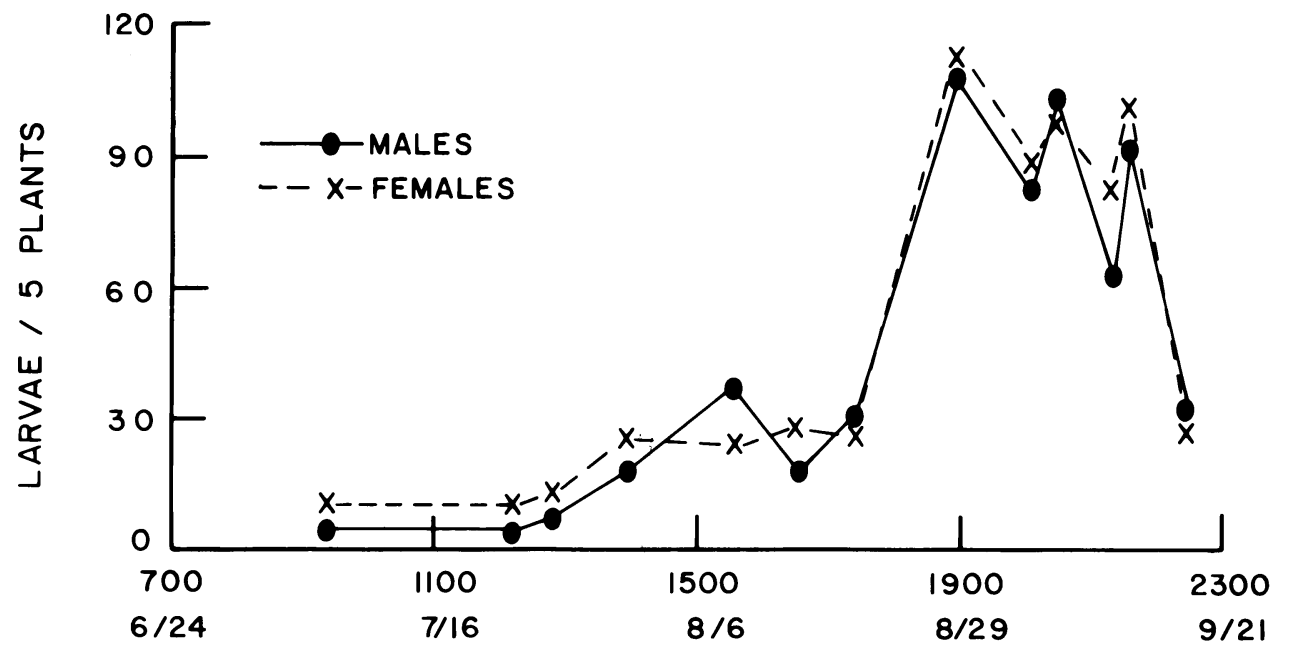

PHYSIOLOGICAL TIME

Fig. 7. Numbers of male and female pink bollworm larvae (from dissected cotton fruit) are plotted on cummulative degree-days.

veloped to flowering stage, pollinated normally, and bolls formed (see also Noble, 1969). By the fourth generation, uninfested bolls became scarce, and the number of pink bollworms decreased.

\section{Sex ratio}

Reproductive potential depends on the ratio of female to male pink bollworms. Pink bollworm larvae were collected from dissected fruit and sexed in the laboratory. The abundance of male and female pink bollworms from the west field can be noted in Figure 7 . Statistical analysis (a chi-square test) suggests that there was no significant difference in the expected frequency $(1: 1)$ of males and females in either the west end $\left(\chi^{2}=16.85, \mathrm{df}=12, \mathrm{p}=.12\right)$ or in the east end $\left(\chi^{2}=7.86, \mathrm{df}=10, \mathrm{p}=\right.$ $.52)$ of the field, nor did this frequency change appreciably during the season.

\section{Quantifying the interactions}

Pink Bollworm-induced fruit abscission-The pink bollworm infestation did not significantly increase shed rates, when all categories of fruit age were considered (Table 2). A three dimensional chi-square test $\left(\chi_{2 \times 2 \times 9}^{2}=0.270\right.$, $\mathrm{df}=1, \mathrm{p}=.60)($ Table 2) was used in the analysis. By contrast, Butler and Henneberry (1976) reports that 60 percent as many infested blooms set bolls as did blooms that were not infested. A further analysis of the current data using a paired Z-test of each individual fruitage category reveals that $\mathrm{Sc}, \mathrm{Fl}$, and $\mathrm{Ba}$ showed significant differences in shed rates for infested and non-infested fruit (Table 3). It is noteworthy that the negative chi-square value of $\mathrm{Sc}$ indicates a significant shedding of fruits when infested by the pink bollworm; however, $\mathrm{F} 1$ and $\mathrm{Ba}$ were retained at significantly greater rates when infested.

While the results of the nine independent tests $(\alpha=0.45)$ indicated increased retention of the flower and small-boll stage, little extra retention would be expected to occur in the field since these stages are rarely attacked in the field (the flower stage is short-one day) and the small boll stage is not preferred (see following sections). Sc was not heavily infested, because it was also not preferred and occurred during the early season when pink bollworm populations 
TABLE 2.

COMPARISON OF FRUIT STAGE AND SIZE AND SHED RATE (CUMULATIVE VALUES) IN 14 TRIALS OF INFESTED AND NON-INFESTED COTTON FRUIT SUMMER, 1975; TEMPE, ARIZONA

\begin{tabular}{|c|c|c|c|c|c|c|}
\hline \multirow{2}{*}{$\begin{array}{l}\text { Stage of } \\
\text { fruit and } \\
\text { size }\end{array}$} & \multicolumn{3}{|c|}{ Infested } & \multicolumn{3}{|c|}{ Not infested } \\
\hline & Shed & Not shed & Shed & Shed & Not shed & Shed \\
\hline & \multicolumn{2}{|c|}{ Number } & Percent & \multicolumn{2}{|c|}{ Number } & Percent \\
\hline $\mathrm{Sa}$ & 31 & 38 & 43.4 & 13 & 22 & 37.1 \\
\hline $\mathrm{Sb}$ & 54 & 38 & 59.8 & 13 & 15 & 42.8 \\
\hline Sc & 57 & 35 & 61.9 & 9 & 18 & 33.3 \\
\hline Sd & 50 & 44 & 53.2 & 14 & 18 & 43.7 \\
\hline Fl & 13 & 72 & 15.3 & 5 & 15 & 25.0 \\
\hline $\mathrm{Ba}$ & 23 & 65 & 26.9 & 16 & 16 & 50.0 \\
\hline $\mathrm{Bb}$ & 14 & 76 & 15.5 & 3 & 16 & 11.8 \\
\hline $\mathrm{Bc}$ & 0 & 90 & 0 & 0 & 21 & 0 \\
\hline $\mathrm{Bd}$ & 0 & 102 & 0 & 0 & 18 & 0 \\
\hline
\end{tabular}

NOTE: Summary of Chi-square tests performed on above data: $:^{1,2}$

Infestation as a function of fruit size $\chi^{2}=285.42$

$\chi^{2}(.05, \mathrm{df} 8)=15.51$ (interaction indicated)

Shed rate as a function of infestation $\chi^{2}=0.27$

$\chi^{2}(.05, \mathrm{df} 1)=3.84$ (no interaction indicated)

${ }^{1}$ Three dimensional chi-square test based on log-linear models as presented in discrete multivariate analysis.

${ }^{2}$ Data analysed with a computer program written by Dr. S. Selvin, Department of BiomedicalEnvironmental Health Sciences, University of California, Berkeley.

TABLE 3.

Z-TEST PAIRWISE ANALYSIS OF FRUIT SHED IN RELATION TO INFESTATION

\begin{tabular}{ccl}
\hline Fruit size & Z-value $^{*}$ & \multicolumn{1}{c}{ Interaction } \\
& & \\
\hline $\mathrm{Sa}$ & 0.769 & None \\
$\mathrm{Sb}$ & 1.14 & None \\
$\mathrm{Sc}$ & 2.63 & Significant fruit shed \\
$\mathrm{Sd}$ & 0.92 & None \\
$\mathrm{Fl}$ & -7.61 & Significant retention \\
$\mathrm{Ba}$ & -4.09 & Significant retention \\
$\mathrm{Bb}$ & -0.03 & None \\
$\mathrm{Bc}$ & 0 & None \\
$\mathrm{Bd}$ & 0 & None \\
& & \\
\hline
\end{tabular}

"Rejection region $-1.96 \leq \mathrm{Z} \leq 1.96$. Due to high alpha level $(=.45)$, these results indicate trends only and should not be interpreted in a quantitative manner. 


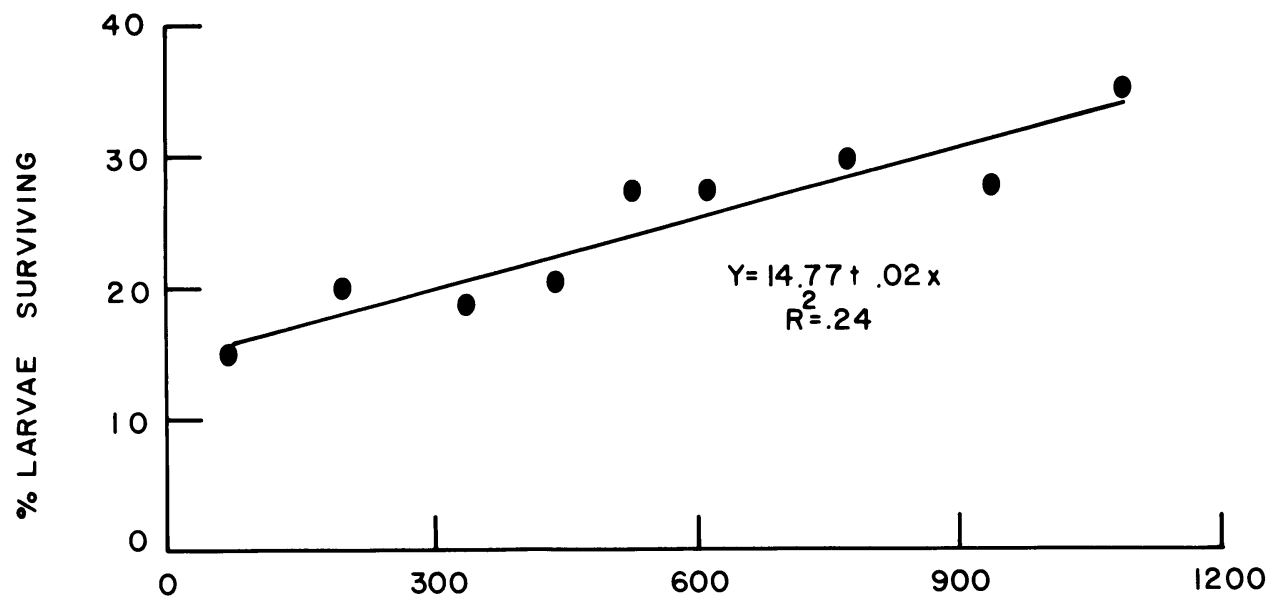

FRUIT AGE (DAY DEGREES)

Fig. 8. Regression equation showing the percent of pink bollworm larvae surviving (mean values) in relation to fruit age in degree-days.

were low. The combined results of these two tests indicated that the square stage of flower to boll is the most vulnerable time for damage by the pink bollworm. Overall, PBW did not significantly affect shed rates.

\section{Pink bollworm survivorship as a function of fruit age}

The survivorship of all first instar larvae within the fruits is shown as a function of fruit age in Figure 8. A linear regression of pink bollworm survivorship on fruit age accounts for approximately 24 percent of the variation $\left(R^{2}=0.24\right.$, all replicates used). A subsequent $\mathrm{t}$-test for regression indicates the slope of the line was not zero $(\mathrm{t}=6.953, \mathrm{df}=\mathrm{two}$-tailed test, $\alpha=.05$ ), while a test for linearity $(\mathrm{F}=.713, \mathrm{~F}(.05 \mathrm{df} 7,90)=2.11)$ supports the linear model assumption that survivorship increased as the age of the fruit increased.

\section{Pink bollworm preference and fruit age}

Fruit-age preference refers primarily to the age of fruit chosen by the adult fe- male for oviposition, as little between fruit migration by larvae occurs. Many investigators have reported the distribution of pink bollworm ovipositional sites on cotton plants (Lukefahr, 1957; Fenton and Owen, 1953; Brazzel and Martin, 1957; and McLaughlin, 1972). The latter two investigators discussed the seasonal distribution of ovipositional sites. Fenton and Owen (1953) found 88.4 percent of the pink bollworm eggs were deposited under the calyxes of bolls. Other investigators have reported at least 50 percent of the pink bollworm eggs oviposited on bolls (Loftin, 1921 and Hunter, 1926). In the absence of bolls, the female will oviposit indiscriminately on the foliage of the cotton plant (Fenton and Owen, 1953).

Because pink bollworm eggs are difficult to find, preference was not estimated directly in the field. A computer program was developed to backtrack the ages of both fruit and larvae to determine the age of the fruit when first attacked (see the Appendix). The problem is complicated by the fact that developmental times of the larvae vary in different age fruit (Lukefahr, 1963) and by the fact that several ages of larvae can be found in bolls. Using these methods, more than 98 percent of the 1,037 larvae dis- 


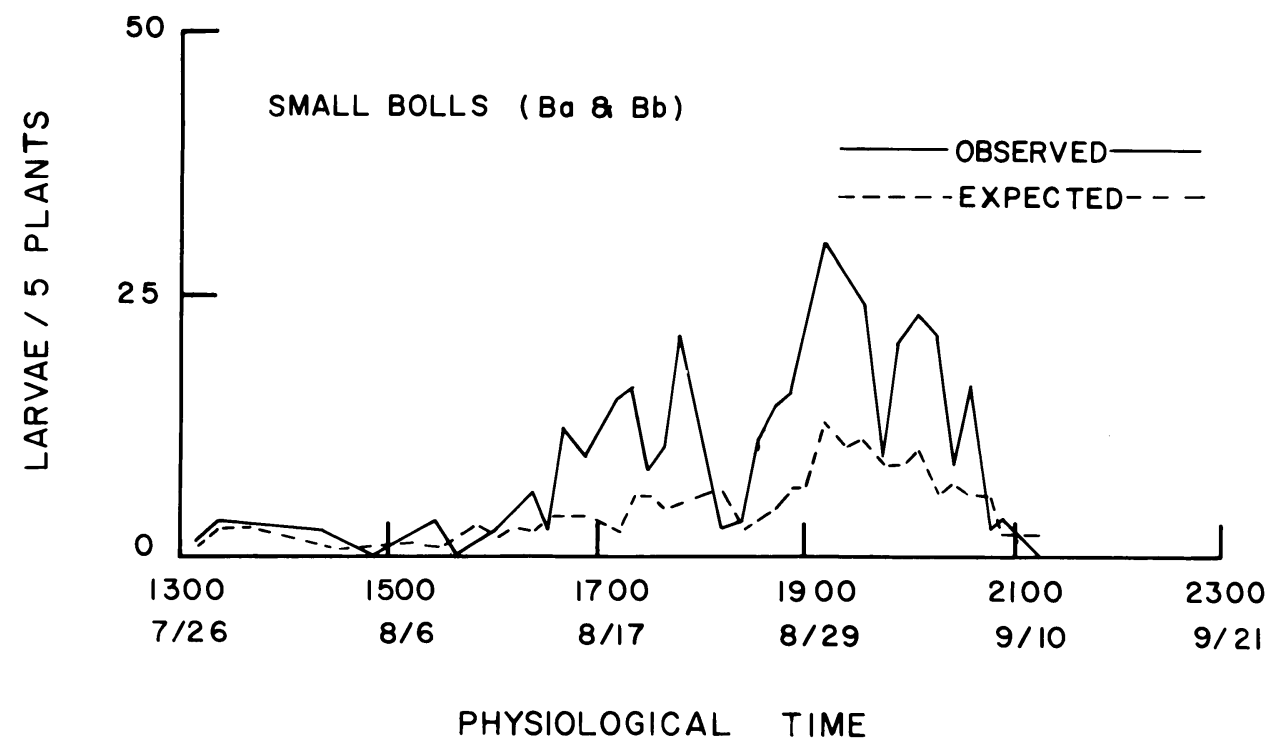

Fig. 9. Observed and expected number of pink bollworm larvae found in small bolls (per 5 plants) are plotted on cummulative degree-days.

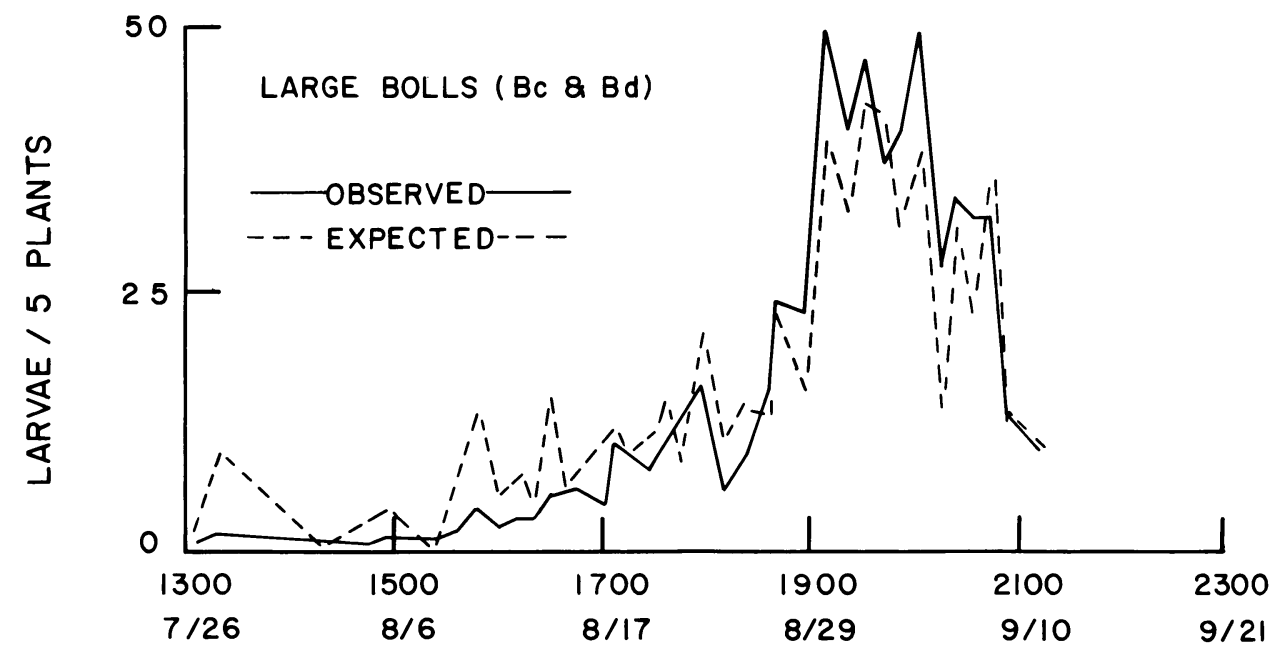

PHYSIOLOGICAL TIME

Fig. 10. Observed and expected number of pink bollworm larvae found in large bolls (per 5 plants) are plotted on cummulative degree-days.

sected from fruit were estimated to have infested bolls, but $\mathrm{Ba}$ and Bd accounted for only 3 percent of the total bolls infested. Intermediate age bolls $\mathrm{Bb}$ and $\mathrm{Bc}$, ranging from 11 to $30 \mathrm{~mm}$ in diameter and approximately 695 to $1027 \mathrm{D}^{\circ}$ in age, respectively, were preferred for infestation. Preference for $\mathrm{Bb}$ and $\mathrm{Bc}$ was also reported by McLaughlin (1972). Figures $9-10$ show the number of pink bollworms infesting small and large bolls.

Total numbers of pink bollworms found in each age category of fruit technically cannot be considered as a true indication of preference without comparing it with some expected value cor- 
TABLE 4 .

PINK BOLLWORM PREFERENCE RATIOS ( $\phi)$ TO TWO SIZES $\left(B_{b}\right.$ AND $\left.B_{c}\right)$ OF COTTON BOLLS

\begin{tabular}{|c|c|c|}
\hline \multirow{2}{*}{ Julian days } & \multicolumn{2}{|c|}{ Preference ratio (observed/expected) ${ }^{*}$} \\
\hline & $\mathrm{B}_{\mathrm{b}}$ & $\mathbf{B}_{\mathrm{c}}$ \\
\hline $225-229$ & 2.38 & 1.87 \\
\hline $230-234$ & 2.87 & 1.13 \\
\hline $235-239$ & 1.91 & 1.28 \\
\hline $240-244$ & 2.73 & 0.85 \\
\hline $245-249$ & 2.16 & 0.82 \\
\hline \multirow[t]{2}{*}{$250-254$} & 1.60 & 1.04 \\
\hline & $\overline{\mathrm{X}} \overline{2.28}$ & $\overline{1.17}(\mathrm{LSD}=0.43) \uparrow$ \\
\hline
\end{tabular}

*The preference ratio is defined as the observed number of larvae in fruit of specific age divided by the calculated number of larvae expected in that age category.

tEvidence for a difference is significant $(\mathrm{LSD}=0.43)$.

TABLE 5 .

DISTRIBUTION OF PINK BOLLWORM LARVAE AND METHODS OF ENTRY IN COTTON SQUARES

\begin{tabular}{|c|c|c|c|c|c|c|}
\hline \multirow{2}{*}{$\begin{array}{c}\text { Fruit stage } \\
\text { and size }\end{array}$} & \multicolumn{4}{|c|}{ Number of PBW larvae feeding on: } & \multicolumn{2}{|c|}{ Entering squares: } \\
\hline & Anthers & Pistil & Petals & Ovary & Laterally & $\overline{\text { Apically }}$ \\
\hline Sa & 19 & 1 & 0 & 0 & 15 & 5 \\
\hline $\mathrm{Sb}$ & 20 & 0 & 0 & 0 & 15 & 5 \\
\hline Sc & 20 & 0 & 0 & 0 & 15 & 5 \\
\hline Sd & 20 & 10 & 0 & 1 & 17 & 3 \\
\hline $\begin{array}{l}\text { Rosetted } \\
\text { flowers }\end{array}$ & 70 & 70 & 65 & 3 & - & - \\
\hline $\begin{array}{l}\text { Post-Bloom } \\
\text { rosetted flowers }\end{array}$ & - & - & - & 25 & - & - \\
\hline
\end{tabular}

rected for fruit availability. Preference ratios $\phi$ were calculated based on the relative abundance of available fruit. These ratios for each date are the number of larvae observed to emerge from each fruit age class in the field divided by the number of larvae that would have been expected to emerge from each category if all categories were attacked at the same frequency as they occurred in the field (i.e., no preference). Figures 9 and 10 show the observed number of pink bollworms compared to the expected number for both small bolls and large bolls, respectively. A value greater than 1 would indicate preference, while a value 
less than 1 would indicate avoidance. A two-way analysis of variance of the preference ratios (column effects) in relation to time (row effects) showed that preference for $\mathrm{Bb}$ was significantly greater than for Bc (column effect: $F=19.096, F$ $(.05, \mathrm{df} 1,5)=6.61)$, and that no effect was measured for different times in the season (row effect: $F=0.983, F(.05$, df 1,5$)=5.05)($ Table 4$)$.

\section{Pink bollworms in squares}

Noble (1969) reported that most infested squares developed to flowering stage with normal pollination and boll formation. Twenty fruits each of $\mathrm{Sa}, \mathrm{Sb}$,
Sc, and Sd, 70 rosetted blooms, and 50 post-bloom rosetted (purple) flowers (infested, but no longer occupied by the pink bollworm) were dissected and examined for feeding damage and means of entry. Lateral entry into the square was most common (Table 5). Anthers were the preferred structure for feeding in all categories of squares. A combination of anther and pistil-feeding was found in Sd, while a combination of anther, pistil, and petal feeding occurred in rosetted blooms. Dissections of developing bolls revealed that usually one ovary was injured when feeding occurred in the largest square, but three ovaries were damaged in the rosetted blooms (Table 5).

\section{DISCUSSION}

This investigation and other published ones reveals a close adaptation between the two species-cotton and pink bollworm. For example, pink bollworm did not significantly affect shed rates of preferred stages of cotton fruit, and significantly increased retention of the nonpreferred flower and small boll stages. The preference studies indicated that less than 3 percent of the non-preferred flowers and small boll stages were attacked. Results from our experiments substantiate observations by Noble (1969), that the pink bollworm attacks on fruit did not increase shedding, because only nonvital structures of the developing square were eaten, thus regular boll formation was not prevented. Also noteworthy is the fact that the pink bollworm does not change plant growth patterns (Gutierrez et al. 1975). Earlier work (Brazzel and Gaines, 1956) showed that infestation levels up to 50 percent infested bolls (less than two larvae per infested boll) caused relatively small decreases in value of cotton.

Adaptation frequently tends to be mutual. It is not surprising, therefore, that survival, developmental times, fecundity and other biological attributes are regulated by patterns of fruit avail. ability in cotton plants. Survival is greatest in the larger bolls, which are also the most preferred (more than 98 percent of the larvae-infested bolls), hence larval mortality due to abscission is minimized. In addition, the pink bollworm completes its development most rapidly in the larger categories of bolls.

The close behavioral and physiological relationship of the pest and plant greatly influences the dynamics of pink bollworm populations. This can be clearly demonstrated by the fact that infested squares are not shed prematurely, which works to the advantage of the pink bollworm because 1) this shedding would adversely decrease population numbers during the critical early season (i.e., the larvae in the shed squares would probably die prematurely); and 2) the fruit would not be available as preferred bolls later in the season for the later PBW generations to infest. 


\section{LITERATURE CITED}

ADKISSON, P. L.

1960. The effect of pink bollworm infestation on cotton produced under high moisture conditions. Texas Agr. Exp. Sta. Prog. Rpt. 2156, 7 pp.

1961. Fecundity and longevity of the adult female pink bollworm reared on natural and synthetic diets. Jour. Econ. Ent. 54: 1224-27.

BRAZZEL, J. R., and D. F. MARTIN

1955. Behavior of pink bollworm larvae. Jour. Econ. Ent. 48:677-79.

BRAZZZL, J. R., and J. C. GAINES

1956. The effects of pink bollworm infestations on yield and quality of cotton. Jour. Econ. Ent. 49:852-54.

BUTLER, G. D., JR., and A. G. HAMILTON

1976. Temperature dependent development rates for four strains of Pectinophora gossypiella, Ann. Ent. Soc. Amer. 69(3):450-52.

BUTLER, G. D., JR., and T. J. HENNEBERRY

1976. Biology, behavior, and effects of larvae of pink bollworm in cotton flowers. Environ. Ent. 5(5):970-72.

CAMPBELL, A., B. D. FRASER, N. GILBERT, A. P. GUTIERREZ, and M. P. MACKAUER

1974. Temperature requirements of some aphids and their parasites. Jour. Appl. Ecol. 11:431-38.

FENTON, F. A., and W. L. OWEN, JR.

1953. The pink bollworm of cotton in Texas. Texas Agr. Exp. Sta. Misc. Publ. 100 pp.

GUTIERREZ, A. P., L. A. FALCON, W. LOEW, P. A. LEIPZIG, AND R. VAN DEN BOSCH

1975. An analysis of cotton production in California: A model for Acala cotton and the effects of defoliators on its yield. Environ. Ent. 4:125-36.

GUTIERREZ, A. P., G. D. BUTLER, JR., Y. WANG, and D. WESTPHAL

1977. The interaction of pink bollworm, cotton and weather. Can. Ent. 109(11): 1457-66.

HUNTER, W. D.

1926. The pink bollworm, with special reference to steps taken by the Department of Agriculture to prevent its establishment in the United States. U.S. Dept. Agr. Bull. 1397, 30 pp.

LOFTIN, U. C., K. B. McKINNEY, and W. K. HANSON

1921. Report on investigations of the pink bollworm of cotton in Mexico. U.S. Dept. Agr. Bull. 918. 64 pp. LUKEFAHR, M.

1957. Mating and oviposition habits of the pink bollworm moth. Jour. Econ. Ent. 50:487-90.

1962. Pink bollworm development in relation to age of squares and bolls with notes on biology. Jour. Econ. Ent. 55:158-59.

LUKEFAHR, M., and J. A. GRIFFIN

1956. The effects of food on longevity and fecundity of pink bollworm moths. Jour. Econ. Ent. 49:876-77.

LUKEFAHR, M., and D. F. MARTIN

1963. Evaluation of damage to lint and seed of cotton caused by the pink bollworm. Jour. Econ. Ent. 56:710-13

McLAUGHLIN, J. R.

1972. Bionomics of the pink bollworm, Pectinophora gossypiella (Saunders), in the southern desert NOBLE, L. W. region of Califiornia. Doctoral dissertation. Univ. of California at Riverside. 98 pp.

1969. Fifty years of research on the pink bollworm in the United States. USDA Agr. Hndbk. 357. 62 pp.

SLOSSER, J. E., and T. F. WATSON

1971. Population growth of the pink bollworm. Ariz. Agr. Exp. Sta. Tech. Bull. 32 pp.

WANG, Y., A. P. GUTIERREZ, G. OSTER, and R. DAXI

1977. A general model for plant growth and development: Coupling cotton-herbivore interactions. Can. Ent. 109:1359-74. 


\section{APPENDIX}

To compute the age of each fruit selected by the adult PBW moth as an oviposition site, we must observe the date $\left(t_{c}\right)$ and age $\left(A_{f}\right)$ of all fruit when collected, as well as the date of pupation $\left(t_{p}\right)$ and or emergence $\left(t_{e}\right)$ of each larva from that fruit. These data are used to compute the age $\left(A_{C}\right)$ of the larvae at the time the fruit was collected in the field, and this information in turn is used to calculate the age of the fruit $\left(\mathrm{F}_{i}\right)$ at the time of oviposition. Computations are complicated by the differing developmental rates of larvae in different age fruit (see Lukefahr, 1962, and Gutierrez et al. 1977).

Each larva accumulates $A_{i}$ day degrees of age during incubation (on artificial medium from the time it is collected at time $t_{c}$ until it pupates at $t_{p}$ or emerges at $t_{e}$ (Equations A.1-2)

$$
\begin{aligned}
& A_{i}=\left(t_{p}-t_{c}\right) \cdot K \\
& A_{e}=\left(t_{e}-t_{c}\right) K
\end{aligned}
$$

, where $\mathrm{K}$ is the number of day degrees accumulated per day.

From this information, we can compute larval age $\left(\mathrm{A}_{\mathrm{C} 1}\right)$ at collection (A.3)

$$
\mathrm{A}_{\mathrm{C} 1}=\mathrm{T}_{\mathrm{p}}-\mathrm{A}_{\mathrm{i}}
$$

, where $T_{p}$ is the average time required to mature from egg to pupa (i.e., $322 \mathrm{D}^{\circ}$ ). A further estimate $\left(A_{C 2}\right)$ can be obtained from $A .4$, where $T_{a}$ is the time from egg to adult emergence $\left(450 \mathrm{D}^{\circ}\right)$

$$
\mathrm{A}_{\mathrm{C} 2}=\mathrm{T}_{\mathrm{a}}-\mathrm{A}_{\mathrm{e}}
$$

The average age $(\overline{\mathrm{AC}})$ at collection is $\frac{A C+A C 2}{2}$

To compute the age of the fruit selected for oviposition we follow a similar logic. The amount $\left(\mathrm{F}_{\mathrm{a}}\right)$ of age accumulated by the fruit from the time the egg was deposited on it and the time it was collected may be computed from A.5.

$$
\mathrm{F}_{\mathrm{a}}=\overline{\mathrm{A}}_{\mathrm{C}} \cdot \mathrm{K}_{\mathrm{r}}
$$

, where $\mathrm{K}_{\mathrm{r}}$ is the ratio of insect developmental rate to that of the plant (i.e., 0.833). The age $\left(\mathrm{F}_{\mathrm{i}}\right)$ of the fruit selected by the adult moth is computed by A.6.

$$
\mathrm{F}_{\mathrm{i}}=\mathrm{A}_{\mathrm{f}}-\mathrm{F}_{\mathrm{a}} \mathrm{K}_{\mathrm{d}}
$$

, where $\mathrm{K}_{\mathrm{d}}$ is a correction factor for varying developmental rates of the larvae in different age fruit (see Table 1 for the values of this variable). 